\title{
Male factor infertility in the Comprehensive Procreational Health Protection Program at the University Hospital in Cracow
}

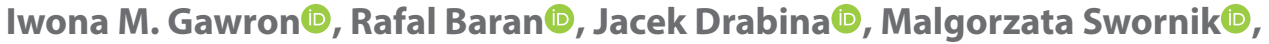 \\ Ewa Posadzka@, Robert Jach(1)
}

Collegium Medicum, Jagiellonian University, Cracow, Poland

\begin{abstract}
Objectives: Quality of semen is one of the most important factors contributing to couples' chance of natural conception. There are many confirmed or potential factors that influence semen analysis results. To estimate the incidence and analyze male factor infertility.

Material and methods: The retrospective observational study was in the Clinical Department of Gynecological Endocrinology and Gynecology, University Hospital in Cracow. The study included men from subfertile population, aged $\geq 18$ years, without prior diagnosis and obvious cause of infertility, whose initial seminograms were used to characterize the population. Seminograms of men remaining in the follow-up were used to analyze the variability of sperm parameters in relation to lifestyle modification and the use of fertility supplements containing antioxidants. Control semen tests were performed at 1-3-month intervals.

Results: The study included 870 men. In $68.5 \%$ of men, at least one abnormal sperm parameter was found and $40.7 \%$ had complex sperm abnormalities. Averaged values of sperm parameters of men from subfertile couples were within the WHO reference ranges, except for the normal morphology, whose median was 3.8\%. No significant differences in the selected sperm parameters after the implementation of conservative management were observed. The percentage of pregnancies not resulting from IVF in the follow-up population was $7.7 \%$.

Conclusions: One semen sample is representative of an individual in the diagnostics of male infertility. Expectant management and lifestyle modification should not be proposed as first-line treatment when more effective procedures are available.
\end{abstract}

Key words: male infertility; semen parameters; natural conception

Ginekologia Polska 2022; 93, 7: 531-539

\section{INTRODUCTION}

Reference Center of Infertility Treatment at the University Hospital in Cracow was the implementer of the National Program for the Comprehensive Protection of Procreational Health for the years 2016-2020. This program was aimed at not only diagnostics, but also treatment of infertility and was dedicated to couples in cohabitation, who for at least 12 months of regular unprotected intercourse, were unable to achieve pregnancy [1] and had no previous medically established diagnosis of infertility. The main assumption of the program was to reduce the number of couples affected by infertility.

Among the factors contributing to couples' chance of natural conception, the most important are woman's age, length of time-to-pregnancy period and quality of semen [2]. The inability of a man to elicit a pregnancy in a healthy female partner defines male infertility [3], thus the evaluation of man's reproductive potential is an inseparable element of assessing couple's fertility and the result of semen analysis is believed to correlate with the chance of conceiving [4]. There are a number of conditions leading to impaired spermatogenesis. Abnormal semen parameters may be the result of hypergonadotropic hypogonadism (primary testicular failure), where there is no possibility of improving fertility, hypogonadotropic hypogonadism (secondary testicular failure), where hormonal treatment is used and normogonadotropic hypogonadism (mostly abnormal sperm parameters of unknown cause), where hormonal

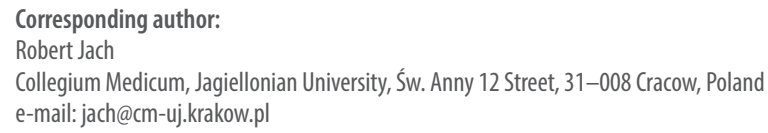


treatment is usually ineffective. In any case of an abnormal seminogram, the patient should be examined by a urologist to exclude pathologies of reproductive functions and to implement treatment of detected disorders, if possible [5].

In addition to several well-documented causes, there are numerous environmental, occupational and lifestyle factors that through a negative effect on spermatogenesis lead to subfertility, limiting reproductive capacity of a couple and contributing to the diagnosis of idiopathic male infertility.

Data from literature indicate an oxidative stress as the cause of reduced male fertility in the above-mentioned conditions, a significant part of which are partially modifiable lifestyle elements [6]. Reactive oxygen species had been shown to disrupt sperm function and motility, damage cell membranes and DNA. Scientific studies had shown that in some situations, antioxidant treatment can improve sperm parameters and increase the chance of pregnancy, however, there is no consensus on dose, duration of treatment, nor qualitative composition of combined oral antioxidants [7]. An important element in the management of idiopathic male infertility is therefore counselling on modifiable risk factors that have a negative long-term effect on overall health [8].

Other factor with potential impact on semen parameters is the alteration of sperm parameters over time [9] due to lifestyle, environmental and genetic factors [10].

Considering that the main goal of couples seeking medical help in Reference Center of Infertility Treatment was not only to determine the cause of reduced fertility, but primarily to achieve pregnancy in a situation where in vitro fertilization (IVF) was not financed by public funds, it was deemed justified to conduct a retrospective study and its objectives were defined.

\section{Objectives}

The main aim of the study was to estimate the incidence of the male factor and its cause in the population of men from infertile couples examined in the Comprehensive Procreational Health Protection Program. Other specific research objectives were:

1. Analysis of the variability of sperm parameters over time and the relationship between the alteration of sperm parameters and lifestyle modification.

2. Estimation of the effectiveness of therapy with oral antioxidants in terms of improving sperm parameters in men with idiopathic subfertility.

3. Calculation of the percentage of clinical pregnancies (not resulting from the use of IVF procedures).

\section{MATERIAL AND METHODS}

The retrospective observational study was conducted based on the data of the Clinical Department of Gynecologi- cal Endocrinology and Gynecology over a period of time from March 1, 2017 to March 1, 2020. The positive opinion of the Bioethical Committee of the Jagiellonian University no. 1072.6120.94.2020 was obtained. The study group consisted of men living in subfertile couples seeking medical help at the University Hospital's Infertility Treatment Center. The following inclusion criteria were used: i) age at least 18 years old, ii) living in a relationship in which pregnancy has not been achieved despite regular unprotected intercourse for at least 12 months, iii) no prior diagnosis and treatment of infertility, iv) no obvious cause of infertility. No exclusion criteria were applied.

The study population was characterized in relation to age and the following semen parameters: volume $(\mathrm{mL})$, liquefaction time (min.), $\mathrm{pH}$, abstinence (days), viscosity, sperm count in $1 \mathrm{ml}$ of ejaculate (million/ml), total sperm count in ejaculate (million), motility (\%), morphology (\%), teratozoospermia index (TZI) [3], multiple anomaly index (MAI), defined as the average number of abnormalities per abnormal sperm $[3,11]$, head defects (\%), midpiece defects (\%), tail defects (\%), cytoplasmic droplets (\%), vitality (\%).

In order to maintain the repeatability of the evaluated parameters, more advanced computer-assisted sperm analysis (CASA) parameters and results of additional sperm tests were not considered.

In the next step, medical documentation of men who underwent extended diagnostics were analyzed. During follow-up visits it was recommended to use one of common antioxidant supplements, to quit smoking, reduce body weight, increase physical activity and modify dietary and working habits, if applicable. Control semen analyses were performed at 1-3-month intervals. By analyzing the change in semen parameters, the effectiveness of the management was assessed. Finally, the percentage of clinical pregnancies not attributable to IVF techniques was calculated.

\section{Semen analysis}

Sperm samples were processed in accordance with WHO guidelines [3] and assessed by means of Sperm Class Analyzer ${ }^{\circledR}$ CASA System. In cases of very low semen parameters manual seminograms were performed. All semen analyses were performed by the person with the statutorily required qualifications [12], trained to work in an embryological laboratory in accordance with the standards of the Polish Society of Reproductive Medicine and Embryology [13] and the European Society of Human Reproduction and Embryology [14].

\section{Qualification}

Couples seeking help because of presumed subfertility were consulted by a supervising obstetrician-gynecologist. 
All men with an incorrect seminogram were referred for urological consultation. Complementary tests including examination of male genitals, rectal examination, transrectal and scrotal ultrasound were performed by a urologist, who managed further treatment, and ordered hormonal and genetic testing, if necessary.

\section{Statistical analysis}

Descriptive statistics methods were used to characterize the male population. Categorical variables were summarized as the number of cases ( $\mathrm{n}$ ) and percentage (\%). Continuous variables were presented using means and standard deviations (SD) in the case of normal distribution and medians, lower (LQ) and upper (UQ) quartiles in the other cases. The maximum (max.) and minimum (min.) values of the variables were also given. Kolmogorov-Smirnov test, skewness test, histogram, boxplot and Q-Q plot were used to assess normality.

Partitioning of the variance attributable to intra-individual variability and inter-individual variability was estimated using ANOVA estimation methodology. Significance of inter-individual to intra-individual variability ratio was estimated using $\mathrm{F}$ test. Assessment of differences in sperm count, progressive motility and normal forms between three or more measurements, without inclusion of lifestyle factors, was done using General Linear Model for Repeated Measurements (GLM-RM) for normally distributed variables and Friedman's Two-way Analysis of Variance by Ranks in other cases, with the Bonferroni correction when appropriate. GLM-RM was used to assess factors affecting average level of above-mentioned parameters when dependent variable had normal distribution in all measurements and Generalized Estimating Equations (GEE) was used in other cases. IBM SPSS Statistics 25 for Windows was used for the calculations.

\section{RESULTS}

\section{Characteristics of the studied population}

Using inclusion and exclusion criteria a database of seminograms was created, representative of 870 men who had done semen analysis at least once.

Population characteristics were based on the results of the initial semen analysis (Tab. $1 \mathrm{~A}-\mathrm{C}$ ). Considering the parameters of sperm motility, morphology and viability, the population was classified according to the diagnoses presented in Table 2. During the extended diagnostics, a few cases of urological disorders were found (Tab. 3). Among men diagnosed with azoospermia and cryptozoospermia, only 3 out of 18 patients came for hormone level testing and in all cases FSH concentrations exceeded the reference range. Patients with azoospermia and cryptozoospermia were also referred for genetic testing and, among patients who performed it (3/18), not a single case of abnormal karyotype or deletion in the AZF region of the $\mathrm{Y}$ chromosome was found.

Seventy-two $(72 / 870 ; 8.28 \%)$ out of 870 men remained in the follow-up including at least three semen tests, performed at 1-3-month intervals. For 65 out of them, some extra data concerning lifestyle factors and pregnancy rate were collected in Table 4. The mean body weight was $78.7 \mathrm{~kg}$ $(S D=9.8)$, and the average frequency of physical activity was 2.0 days a week $(S D=1.6)$. In addition to the data included in the table, one man quit smoking and one man took clomiphene acetate.

In the next step, the variability of sperm concentration, morphology and motility over time in patients who had at least three semen analyses were assessed.

In terms of all three analyzed parameters, inter-individual variability dominated over intra-individual, and for sperm concentration and morphology these ratios were statistically significant (Tab. 5).

There was no significant difference in sperm concentration between three consecutive samples. Similarly, no significant difference was observed regarding progressive motility. There was significant difference in terms of sperm morphology ( $p=0.031$ ), however pairwise comparison did not reveal significant differences in particular pairs of measurements (Tab. 6).

Multivariate analysis of factors related to lifestyle revealed that some of them influenced the value of sperm concentration, i.e., measurement time point $(p=0.014)$, change in dietary habits $(p=0.018)$, weight loss $(p<0.001)$, weight at first measurement $(p=0.012)$, physical activity $(p<0.001)$ and interaction between measurement time point and weight at first measurement ( $p=0.018)$, as well as between measurement time point and physical activity $(p<0.001)$. Change in dietary habits was related to lower sperm concentration, whereas weight loss was related to higher sperm concentration, both differences were stable throughout the measurements. Sperm concentration increased with an increase in physical activity and decreased along with increasing body weight at all measurement points. (Tab. 7).

Multivariate analysis revealed that mean progressive motility was associated with the change in dietary habits $(p=0.047)$, whereas impact of body weight was close to significant $(p=0.073$ ). Table 8 presents the differences related to change in dietary habits and body weight difference of 1 kilogram at particular measurement points (Tab. 8).

Multivariate analysis revealed that only a few of lifestyle factors influenced sperm morphology. According to the multivariate model mean percentage of morphologically normal forms was higher in those who smoked $(p=0.019)$, throughout all measurement points. The percentage of mor- 


\begin{tabular}{|c|c|c|c|c|c|c|c|c|}
\hline Variable & Mean & SD & Median & $1^{\text {st }}$ quartile & $3^{\text {rd }}$ quartile & Min. & Max. & $\mathbf{n}$ \\
\hline Age [years] & 34.6 & 5.6 & & & & 22 & 62 & 870 \\
\hline Semen volume $[\mathrm{mL}]$ & 3.49 & 1.66 & & & & 0.40 & 9.93 & 870 \\
\hline pH & 8.0 & 0.2 & & & & 6.8 & 8.9 & 870 \\
\hline Abstinence [days] & & & 3 & 3 & 5 & 0 & 30.0 & 870 \\
\hline Sperm concentration $[\mathrm{m} / \mathrm{n} / \mathrm{mL}]$ & & & 27.3 & 10.0 & 55.4 & 0 & 381.0 & 870 \\
\hline Total sperm number [mln] & & & 88.9 & 30.0 & 177.0 & 0 & 1817.0 & 870 \\
\hline Progressive motility [\%] & 32.7 & 17.0 & & & & 0 & 76.3 & 870 \\
\hline Non-progressive motility [\%] & 11.0 & 6.2 & & & & 0 & 42.6 & 870 \\
\hline Total motility [\%] & 43.7 & 18.2 & & & & 0 & 81.6 & 870 \\
\hline Immobile sperm [\%] & 56.2 & 18.2 & & & & 18.4 & 100 & 870 \\
\hline Rapid progressive motility [\%] & 18.7 & 12.1 & & & & 0 & 64.9 & 777 \\
\hline Slow progressive motility [\%] & 15.8 & 8.3 & & & & 0 & 49.5 & 777 \\
\hline Normal morphology [\%] & & & 3.8 & 2.0 & 5.4 & 0 & 18.0 & 870 \\
\hline TZI & & & 1.63 & 1.48 & 1.82 & 0 & 14.3 & 776 \\
\hline MAI & & & 3.13 & 2.48 & 4.37 & 0 & 67 & 815 \\
\hline Head defects [\%] & & & 93.8 & 90.4 & 96.2 & 0 & 100 & 787 \\
\hline Inlet defects [\%] & & & 45.0 & 35.0 & 54.5 & 0 & 100 & 819 \\
\hline Tail defects [\%] & & & 4.6 & 2.0 & 9.0 & 0 & 60 & 776 \\
\hline Cytoplasmic droplets [\%] & & & 4.1 & 2.0 & 7.0 & 0 & 100 & 776 \\
\hline Vitals forms [\%] & 63.8 & 15.4 & & & & 4.3 & 92.0 & 851 \\
\hline
\end{tabular}

$\mathrm{SD}$ - standard deviation; $\mathrm{TZI}$ - teratozoospermia index; $\mathrm{MAI}$ - multiple anomaly index

\begin{tabular}{|c|c|c|c|}
\hline Variable & Value & $\mathbf{n}$ & Percentage [n/870 \%] \\
\hline \multirow{2}{*}{ Semen volume } & $<1.5$ & 62 & 7.1 \\
\hline & $\geq 1.5$ & 808 & 92.9 \\
\hline \multirow{2}{*}{ Semen pH } & $<7.2$ & 2 & 0.2 \\
\hline & $\geq 7.2$ & 868 & 99.8 \\
\hline \multirow{4}{*}{$\begin{array}{l}\text { Sperm } \\
\text { concentration } \\
{[\mathrm{m} \ln / \mathrm{mL}]}\end{array}$} & $<1$ & 39 & 4.5 \\
\hline & $\geq 1 \&<5$ & 83 & 9.5 \\
\hline & $\geq 5 \&<15$ & 175 & 20.1 \\
\hline & $\geq 15$ & 573 & 65.9 \\
\hline \multirow{2}{*}{$\begin{array}{l}\text { Total sperm } \\
\text { number }[\mathrm{mln}]\end{array}$} & $<39$ & 267 & 30.7 \\
\hline & $\geq 39$ & 603 & 69.3 \\
\hline \multirow{2}{*}{$\begin{array}{l}\text { Progressive } \\
\text { motility [\%] }\end{array}$} & $<32 \%$ & 423 & 48.6 \\
\hline & $\geq 32 \%$ & 447 & 51.4 \\
\hline \multirow{2}{*}{ Total motility [\%] } & $<40 \%$ & 349 & 40.1 \\
\hline & $\geq 40 \%$ & 521 & 59.9 \\
\hline \multirow{2}{*}{$\begin{array}{l}\text { Normal } \\
\text { morphology [\%] }\end{array}$} & $<4 \%$ & 449 & 51.6 \\
\hline & $\geq 4 \%$ & 421 & 48.4 \\
\hline \multirow{2}{*}{ Vital forms [\%] } & $<58 \%$ & 226 & 26.0 \\
\hline & $\geq 58 \%$ & 626 & 72.0 \\
\hline
\end{tabular}

\begin{tabular}{|c|c|c|c|}
\hline Variable & Value & $\mathbf{n}$ & Percentage (n/870 \%) \\
\hline \multirow{3}{*}{$\begin{array}{l}\text { Semen } \\
\text { viscosity }\end{array}$} & Normal & 813 & 93.4 \\
\hline & + & 34 & 3.9 \\
\hline & ++ & 23 & 2.6 \\
\hline \multirow{3}{*}{$\begin{array}{l}\text { Sperm } \\
\text { aggregation }\end{array}$} & None or typical & 778 & 89.4 \\
\hline & + & 83 & 9.5 \\
\hline & ++ & 9 & 1.0 \\
\hline \multirow{10}{*}{$\begin{array}{l}\text { Sperm } \\
\text { agglutination }\end{array}$} & None & 612 & 70.3 \\
\hline & 1 & 3 & 0.3 \\
\hline & $1 \mathrm{~A}$ & 47 & 5.4 \\
\hline & $1 \mathrm{~B}$ & 28 & 3.2 \\
\hline & $1 C$ & 2 & 0.2 \\
\hline & $1 \mathrm{D}$ & 93 & 10.7 \\
\hline & $2 \mathrm{~A}$ & 28 & 3.2 \\
\hline & $2 B$ & 3 & 0.3 \\
\hline & $2 \mathrm{D}$ & 49 & 5.6 \\
\hline & $3 \mathrm{~A}$ & 5 & 0.6 \\
\hline
\end{tabular}


Table 2. Diagnosis by seminogram results in the studied population

\begin{tabular}{|l|c|c|}
\hline Diagnosis & $\mathbf{n}$ & $\mathbf{n} / \mathbf{N} \%$ \\
\hline Azoospermia & 13 & 1.5 \\
\hline Cryptozoospermia & 5 & 0.6 \\
\hline Oligoasthenoteratozoospermia & 182 & 20.9 \\
\hline Oligoasthenozoospermia & 22 & 2.5 \\
\hline Oligoteratozoospermia & 36 & 4.1 \\
\hline Oligozoospermia & 39 & 4.5 \\
\hline Asthenoteratozoospermia & 115 & 13.2 \\
\hline Asthenozoospermia & 86 & 9.9 \\
\hline Teratozoospermia & 98 & 11.3 \\
\hline Normozoospermia & 274 & 31.5 \\
\hline N & 870 & 100.0 \\
\hline
\end{tabular}

\begin{tabular}{|l|c|c|}
\hline \multicolumn{3}{|l|}{ Table 3. Diagnosed urological disorders } \\
\hline Diagnosis & $\mathbf{n}$ & $\mathbf{n} / \mathbf{N} \%$ \\
\hline Varicocele eligible for surgery & 4 & 0.5 \\
\hline Phimosis & 6 & 0.7 \\
\hline Testicular tumor & 2 & 0.2 \\
\hline Retrograde ejaculation & 1 & 0.1 \\
\hline
\end{tabular}

${ }^{*} \mathrm{~N}=870$

Table 4. Characteristics of the follow-up subpopulation in relation to selected parameters studied

\begin{tabular}{|c|c|c|c|}
\hline Variable & Value & $\mathbf{n}$ & Percentage (n/65 \%) \\
\hline \multirow{2}{*}{ Smoking } & no & 60 & 92.3 \\
\hline & yes & 5 & 7.7 \\
\hline \multirow{2}{*}{ Diet modification } & no & 24 & 36.9 \\
\hline & yes & 41 & 63.1 \\
\hline \multirow{2}{*}{ Body weight loss $>3 \mathrm{~kg}$} & no & 47 & 72.3 \\
\hline & yes & 18 & 27.7 \\
\hline \multirow{2}{*}{$\begin{array}{l}\text { Work style habits } \\
\text { modification }\end{array}$} & no & 61 & 93.8 \\
\hline & yes & 4 & 6.2 \\
\hline \multirow{2}{*}{ Fertility supplements } & no & 1 & 1.6 \\
\hline & yes & 64 & 98.4 \\
\hline \multirow{2}{*}{ Other medications } & no & 60 & 92.3 \\
\hline & yes & 5 & 7.7 \\
\hline \multirow{2}{*}{$\begin{array}{l}\text { Pregnancy not resulting } \\
\text { from IVF }\end{array}$} & no & 60 & 92.3 \\
\hline & yes & 5 & 7.7 \\
\hline
\end{tabular}

IVF - in vitro fertilization

phologically normal sperm decreased at the first measurement point with an increase in physical activity, although non-significantly $(p=0.55)$. In the second measurement the percentage of normal sperm slightly increased with an increase of days of physical activity, whereas in the third measurement the percentage of normal sperm was actually independent from men's physical activity (Tab. 9).

Finally, the difference between the value of given parameter (sperm concentration, progressive motility, morphology) from the first semen analysis and the average value of this parameter from subsequent tests was assessed. No significant difference was observed between the value of the first measurement and the average value drawn from subsequent measurements for any parameter (Tab. 10).

\section{Complications}

There were no complications from any of the routine procedures used.

\section{DISCUSSION}

Diagnosis of male infertility due to sperm dysfunction is based on semen analysis. Precise determination of the cause of male infertility proves impossible in $30-40 \%$ of cases [5]. However, the definition of infertility is based on duration of the problem, not on identifying specific disorders or causative agent. The time limit of 12 months in which pregnancy cannot be achieved indicates that there is less than a 5\% chance that the failure is due to random factors [15].

The fifth edition of the WHO Semen Manual gave reference ranges for the most important sperm parameters, determined based on seminograms obtained from a large population of men who conceived within 12 months [3]. The set reference values identify the lower $5 \%$ threshold of one-sided confidence interval in the population of fertile men and should not be interpreted as absolute norms [16]. This means that $5 \%$ of fertile men from reference population who achieved pregnancy within 12 months had values below the cut-off points and therefore outside the "fertile norms".

The first finding of the study was that the semen parameters of the studied subfertile male population were largely within the WHO reference ranges [17]. The detected abnormalities principally concerned sperm morphology, for which population median value of normal forms was $3.8 \%$. However, not all morphological indices were beyond the desired values. TZI index was equal to 1.63 , that was below the WHO maximum value of 1.72 , while median MAI index was above the WHO maximum values of 2.55 [3]. The median percentage value $(4.1 \%)$ of spermatozoa with cytoplasmic droplets (excess residual cytoplasm) [18] was lower than WHO maximum value of $7 \%$ [3].

Among men with no apparent cause of reduced fertility, there are those with abnormal sperm parameters (idiopathic infertility), and those with normal sperm parameters (unexplained infertility) [19]. There are currently no criteria to distinguish between men with disturbed sperm parameters and a high chance for pregnancy from those with poor prognosis. 
Table 5. Inter-individual and intra-individual variability of sperm parameters

\begin{tabular}{|l|c|c|c|c|c|}
\hline Variable & Intra-individual & Inter-individual & $\begin{array}{c}\text { Inter-individual/ } \\
\text { /Total }\end{array}$ & $\begin{array}{c}\text { p value for } \\
\text { Inter-individual/ } \\
\text { /Intra-individual }\end{array}$ & $\begin{array}{c}\text { Inter-individual/ } \\
\text { /Intra-individual }\end{array}$ \\
\hline Sperm concentration & 298.617 & 417.634 & $58.3 \%$ & $139.9 \%$ & 0.046 \\
\hline Progressive motility & 70.860 & 129.653 & $64.7 \%$ & $183.0 \%$ & 0.223 \\
\hline Morphology & 1.223 & 2.461 & $66.8 \%$ & $201.2 \%$ & $<0.001$
\end{tabular}

Table 6. Sperm concentration ( $\mathrm{m} / \mathrm{n} / \mathrm{mL})$, progressive motility (\%) and sperm morphology $(\%)$ in 3 consecutive samples

\begin{tabular}{|c|c|c|c|c|c|c|}
\hline Parameter & Measurement & n & median & Lower quartile & Upper quartile & $\mathbf{p}$ \\
\hline \multirow{3}{*}{ Sperm concentration $[\mathrm{m} / \mathrm{n} / \mathrm{mL}]$} & 1 & 72 & 9.40 & 3.92 & 22.87 & 0.350 \\
\hline & 2 & 72 & 9.09 & 5.52 & 22.13 & \\
\hline & 3 & 72 & 9.58 & 5.26 & 17.49 & \\
\hline Parameter & Measurement & $\mathrm{n}$ & mean & Lower $95 \% \mathrm{Cl}$ & Upper 95\% Cl & p \\
\hline \multirow{3}{*}{ Progressive motility [\%] } & 1 & 72 & 23.315 & 19.922 & 26.708 & 0.677 \\
\hline & 2 & 72 & 24.609 & 21.233 & 27.985 & \\
\hline & 3 & 72 & 24.216 & 21.004 & 27.427 & \\
\hline Parameter & Measurement & n & median & Lower quartile & Upper quartile & $\mathbf{p}$ \\
\hline \multirow{3}{*}{ Sperm morphology [\%] } & 1 & 72 & 2.00 & 1.00 & 3.00 & $0.031^{*}$ \\
\hline & 2 & 72 & 2.00 & 1.00 & 4.00 & \\
\hline & 3 & 72 & 2.13 & 1.27 & 3.94 & \\
\hline
\end{tabular}

* no significant differences in pairs of measurements 1-2, 2-3, 1-3; Cl - confidence interval

\begin{tabular}{|c|c|c|c|c|}
\hline \multirow{2}{*}{ Parameter } & \multirow{2}{*}{ B } & \multicolumn{2}{|c|}{$95 \%$ Wald Cl } & \multirow{2}{*}{$\mathbf{p}$} \\
\hline & & Lower limit & Upper limit & \\
\hline constant & 25.126 & 16.855 & 33.398 & 0.000 \\
\hline [Measurement = 1] & 0 & - & - & - \\
\hline [Measurement = 2] & 8.852 & 0.978 & 16.727 & 0.028 \\
\hline [Measurement = 3] & 14.880 & 4.811 & 24.949 & 0.004 \\
\hline [Diet modification = No] & 0 & - & - & - \\
\hline [Diet modification = Yes] & -9.227 & -16.874 & -1.580 & 0.018 \\
\hline [Body weight loss = No] & 0 & - & - & - \\
\hline [Body weight loss = Yes] & 0.856 & 0.512 & 1.200 & 0.000 \\
\hline Body weight & -0.279 & -0.463 & -0.096 & 0.003 \\
\hline Physical activity & 2.290 & -0.199 & 4.778 & 0.071 \\
\hline [Measurement $=2]{ }^{*}$ Body weight & 0.026 & -0.320 & 0.372 & 0.883 \\
\hline [Measurement $=3]^{*}$ Body weight & -0.237 & -0.572 & 0.098 & 0.166 \\
\hline [Measurement $=2] *$ Physical activity & 7.066 & 2.492 & 11.640 & 0.002 \\
\hline [Measurement $=3$ ] $*$ Physical activity & 10.065 & 5.258 & 14.872 & 0.000 \\
\hline
\end{tabular}

$\mathrm{Cl}$ - confidence interval

The value of a single parameter correlates poorly with a chance of natural conception, but taking into account three parameters (motility, morphology, concentration) probably increases the prognostic value of seminogram $[16,20]$.There are also situations where the seminogram result in an infertile couple may be normal, but the biological potential of the sperm may be impaired due to intracellular abnormalities [21]. For this reason, the prognostic value of basic semen parameters is limited by the influence of sperm characteristics not included in the routine seminogram, 


\begin{tabular}{|c|c|c|c|c|c|}
\hline \multirow{2}{*}{ Measurement } & \multirow{2}{*}{ Parameter } & \multirow{2}{*}{ B } & \multicolumn{2}{|c|}{$95 \% \mathrm{Cl}$} & \multirow{2}{*}{$\mathbf{p}$} \\
\hline & & & Lower limit & Upper limit & \\
\hline \multirow{4}{*}{1} & Constant & 48.133 & 20.170 & 76.095 & 0.001 \\
\hline & {$[$ Diet modification $=0$ ] } & 0 & - & - & - \\
\hline & [Diet modification $=1]$ & -6.371 & -13.488 & 0.746 & 0.078 \\
\hline & Body weight & -0.349 & -0.702 & 0.004 & 0.053 \\
\hline \multirow{4}{*}{2} & Constant & 46.545 & 18.031 & 75.059 & 0.002 \\
\hline & {$[$ Diet modification $=0$ ] } & 0 & - & - & - \\
\hline & [Diet modification $=1]$ & -3.581 & -10.838 & 3.677 & 0.328 \\
\hline & Body weight & -0.296 & -0.656 & 0.065 & 0.106 \\
\hline \multirow{4}{*}{3} & Constant & 43.860 & 17.123 & 70.596 & 0.002 \\
\hline & [Diet modification $=0$ ] & 0 & - & - & - \\
\hline & {$[$ Diet modification $=1]$} & 6.729 & -13.534 & 0.077 & 0.053 \\
\hline & Body weight & -0.275 & -0.613 & 0.063 & 0.109 \\
\hline
\end{tabular}

$\mathrm{Cl}$ - confidence interval

\begin{tabular}{|c|c|c|c|c|}
\hline \multirow{2}{*}{ Parameter } & \multirow{2}{*}{ B } & \multicolumn{2}{|c|}{ 95\% Wald Cl } & \multirow{2}{*}{$\mathbf{p}$} \\
\hline & & Lower limit & Upper limit & \\
\hline (Constant) & 2.748 & 2.024 & 3.471 & 0.000 \\
\hline$[$ Measurement $=1]$ & 0 & - & - & - \\
\hline [Measurement = 2] & -0.412 & -1.028 & 0.203 & 0189 \\
\hline [Measurement = 3$]$ & -0.176 & -0.768 & 0.416 & 0.561 \\
\hline [Smoking = 0] & 0 & - & - & - \\
\hline$[$ Smoking = 1] & 1.972 & 0.319 & 3.624 & 0.019 \\
\hline Physical activity [days/week] & -0.190 & -0.416 & 0.037 & 0.101 \\
\hline$[$ Measurement $=2] *$ Physical activity & 0.275 & 0.036 & 0.514 & 0.024 \\
\hline [Measurement $=3] *$ Physical activity & 0.175 & -0.011 & 0.361 & 0.065 \\
\hline
\end{tabular}

$\mathrm{Cl}$-confidence interval

Table 10. The first measurement and the average value of subsequent measurements for selected parameters

\begin{tabular}{|l|c|c|c|c|}
\hline $\mathbf{p}=\mathbf{0 . 1 1 0}$ & Median & $\mathbf{1}^{\text {st }}$ quartile & $\mathbf{3}^{\text {rd }}$ quartile & $\mathbf{n}$ \\
\hline Sperm concentration [mIn/mL] Measurement 1 & 9.40 & 3.92 & 22.87 & 72 \\
\hline Sperm concentration [mIn/mL] (Mean of measurements 2+) & 9.43 & 6.03 & 22.64 & 72 \\
\hline $\mathrm{p}=0.222$ & Mean & SD & & $\mathrm{N}$ \\
\hline Progressive motility [\%] Measurement 1 & 23.32 & 14.44 & & 72 \\
\hline Progressive motility [\%] (Mean of measurements 2+) & 24.89 & 12.99 & & 72 \\
\hline p=0.233 & Median & $1^{\text {st }}$ quartile & $3^{\text {rd }}$ quartile & $\mathrm{N}$ \\
\hline Morphology [\%] Measurement 1 & 2.00 & 1.00 & 3.00 & 72 \\
\hline Morphology [\%] (Mean of measurements 2+) & 2.27 & 1.36 & 3.67 & 72 \\
\hline
\end{tabular}

SD - standard deviation

e.g., chromatin maturityorDNA fragmentation [22]. Assessment of additional parameters, e.g., DNA, RNA, centrioles is not routinely performed because treatment methods are limited [23].
Nevertheless, despite existing limitations, sperm analysis remains the main test in routine fertility assessment until better diagnostic tools are invented [16]. What can improve the 
prognostic value of sperm analysis by eliminating temporal variability of parameters is to perform it more than once. The above-mentioned variability is caused by physiological processes (intra-individual variability), biological factors (inter-individual variability) or laboratory technique and implies the limited value of a single semen analysis [15]. Two or three semen samples should probably be evaluated prior to diagnosing reduced fertility [22], however, no consensus on this issue was made [24-26]. In this research, the calculations were based on the analysis of a single initial sample [17], but after evaluating semen parameters variability over time (concentration, progressive motility, morphology), no significant intra-population differences were observed. The presented data would indicate that just one semen sample is sufficient for diagnostic purposes.

Literature data indicate that 30 to $80 \%$ of men with idiopathic infertility have an increased concentration of free oxygen radicals [7], therefore during follow-up visits, empiric treatment with fertility supplements and lifestyle modification were recommended. Of the lifestyle factors, only weight loss, diet modification, physical activity and smoking were suitable for calculations, due to the fact that virtually no one changed working environment and that virtually everyone took supplements. It was shown that weight loss and increased physical activity improve sperm concentration and progressive motility, which coincide with the results of some other studies [27, 28]. Interpretation difficulties were caused by the correlation between diet modification and decrease in sperm concentration, as well as smoking and greater percentage of normal forms. While the first may be because it was an unhealthy diet before its change that was the reason for worsened parameters, the second is rather the result of a bias (a small subgroup of smokers, 7/65), making it impossible to extrapolate the data to the general population. Lifestyle factors were measured only once during the study, although value may vary at particular points of measurements, making the estimations imprecise.

An attempt was also made to evaluate the effectiveness of the conducted management by comparing the sperm parameters from the first sperm analysis with the mean of analogous values from subsequent measurements, but no significant difference was observed for any parameter. Therefore, the results presented suggest that proposing conservative management with an eventual change in lifestyle and antioxidants supplementation does not bring measurable benefits in the aspect of improving sperm parameters, not to mention improving fertility.

No consensus was established so far on how to treat male subfertility. In the case of male or idiopathic infertility, the essential available therapy affects a woman and usually involves one of the ART modalities [23]. The therapeutic success of IVF-ICSI technique led to the fact that since 1992 [29], virtually no progress had been made in investigating the underlying etiology of male infertility and, consequently, in methods of treatment. The IVF-ICSI allows to overpass the problem of e.g., reduced concentration or motility but may not be as effective in the case of intracellular defects. Moreover, treatment using IVF-ICSI can significantly burden the household budget, which is an important issue when treatment is not financed from public funds. On the other hand, the expectant procedure provided by public health in situations of complex sperm abnormalities seems to be hardly justified given the existence of more effective treatment methods. Couples with idiopathic infertility or a mild male factor obviously still have a chance of getting pregnant by natural fertilization, but no recognized method has been developed to determine this chance.

\section{CONCLUSIONS}

Limited conclusions can be drawn that the proposed conservative treatment was not effective in improving sperm parameters or that the population of men under observation was too small to draw conclusions. It is therefore reasonable not to propose conservative management as a possible therapeutic approach for couples with a male infertility factor, at least until the development of a technique that allows improving the fertilization capacity of sperm or invention of efficient model defining the chance of natural conception.

\section{Conflict of interest}

The study received no financial support. The authors have nothing to disclose.

\section{Author's role}

I.G.: study conception and design; data collection, analysis and interpretation; article drafting and revision; final approval of the version to be published. R.B.: data collection, analysis and interpretation; article drafting and revision; final approval of the version to be published. J.D.: data collection, analysis and interpretation; article drafting and revision; final approval of the version to be published. M.S.: data collection, analysis and interpretation; article drafting and revision; final approval of the version to be published. E.P.: data collection, analysis and interpretation; article drafting and revision; final approval of the version to be published. $R$. J.: study conception and design; article drafting and revision; final approval of the version to be published.

\section{REFERENCES}

1. Zegers-Hochschild F, Adamson GD, de Mouzon J, et al. International Committee for Monitoring Assisted Reproductive Technology, World Health Organization, International Committee for Monitoring Assisted Reproductive Technology, World Health Organization. The International Committee for Monitoring Assisted Reproductive Technology 
(ICMART) and the World Health Organization (WHO) Revised Glossary on ART Terminology, 2009. Hum Reprod. 2009; 24(11): 2683-2687, doi: 10.1093/humrep/dep343, indexed in Pubmed: 19801627.

2. Vander Borght M, Wyns C. Fertility and infertility: Definition and epidemiology. Clin Biochem. 2018; 62: 2-10, doi: 10.1016/j.clinbiochem.2018.03.012, indexed in Pubmed: 29555319.

3. World Health Organization. WHO laboratory manual for the examination and processing of human semen, 5th ed. World Health Organization 2010.

4. Buck Louis GM, Sundaram R, Schisterman EF, et al. Semen quality and time to pregnancy: the Longitudinal Investigation of Fertility and the Environment Study. Fertil Steril. 2014; 101(2): 453-462, doi: 10.1016/j. fertnstert.2013.10.022, indexed in Pubmed: 24239161.

5. Jungwirth A, Diemer T, Kopa Z, et al. European Association of Urology guidelines on Male Infertility: the 2018 update. European Association of Urology. 2018.

6. Choy JT, Eisenberg ML. Male infertility as a window to health. Fertil Steril. 2018; 110(5): 810-814, doi: 10.1016/j.fertnstert.2018.08.015, indexed in Pubmed: 30316415.

7. Agarwal A, Parekh N, Panner Selvam MK, et al. Male Oxidative Stress Infertility (MOSI): Proposed Terminology and Clinical Practice Guidelines for Management of Idiopathic Male Infertility. World J Mens Health. 2019; 37(3): 296-312, doi: 10.5534/wjmh.190055, indexed in Pubmed: 31081299.

8. Salonia A, Matloob R, Gallina A, et al. Are infertile men less healthy than fertile men? Results of a prospective case-control survey. Eur Urol. 2009; 56(6): 1025-1031, doi: 10.1016/j.eururo.2009.03.001, indexed in Pubmed: 19297076.

9. Levine $\mathrm{H}$, Jørgensen $\mathrm{N}$, Martino-Andrade $\mathrm{A}$, et al. Temporal trends in sperm count: a systematic review and meta-regression analysis. Hum Reprod Update. 2017; 23(6): 646-659, doi: 10.1093/humupd/dmx022, indexed in Pubmed: 28981654.

10. Virtanen HE, Jørgensen N, Toppari J. Semen quality in the 21 century. Nat Rev Urol. 2017; 14(2): 120-130, doi: 10.1038/nrurol.2016.261, indexed in Pubmed: 28050014.

11. Aziz N, Buchan I, Taylor C, et al. The sperm deformity index: a reliable predictor of the outcome of oocyte fertilization in vitro. Fertil Steril. 1996; 66(6): 1000-1008, doi: 10.1016/s0015-0282(16)58697-x, indexed in Pubmed: 8941069.

12. Ustawa z dnia 25 czerwca 2015 r. o leczeniu niepłodności. Dziennik Ustaw 2015 poz. 1087.

13. Polskie Towarzystwo Medycyny Rozrodu i Embriologii. Stanowisko PTMRiE w sprawie wykonywania zawodu embriologa klinicznego w ośrodkach medycznie wspomaganej prokreacji oraz bankach komórek rozrodczych i zarodków w Polsce (22.06.2016 r.). http://www.ptmrie.org. pl/pliki/artykuly/Stanowisko\%20PTMRiE\%20w\%20sprawie\%20wykonywania\%20zawodu\%20embriologa\%20klinicznego.pdf.

14. De los Santos MJ, Apter S, Coticchio G, et al. ESHRE Guideline Group on Good Practice in IVF Labs. Revised guidelines for good practice in IVF laboratories (2015). Hum Reprod. 2016; 31(4): 685-686, doi: 10.1093/humrep/dew016, indexed in Pubmed: 26908842.

15. Björndahl L. What is normal semen quality? On the use and abuse of reference limits for the interpretation of semen analysis results. Hum Fertil (Camb). 2011; 14(3): 179-186, doi: 10.3109/14647273.2011.580823, indexed in Pubmed: 21770820.
16. Niederberger C, Pellicer A, Cohen J, et al. Introduction: IVF's 40th world birthday. Fertil Steril. 2018; 110(1): 4-324.e5, doi: 10.1016/j.fertnstert.2018.05.017, indexed in Pubmed: 29980260.

17. Cooper TG, Noonan E, von Eckardstein S, et al. World Health Organization reference values for human semen characteristics. Hum Reprod Update. 2010; 16(3): 231-245, doi: 10.1093/humupd/dmp048, indexed in Pubmed: 19934213.

18. Rengan AK, Agarwal $A$, van der Linde $M$, et al. An investigation of excess residual cytoplasm in human spermatozoa and its distinction from the cytoplasmic droplet. Reprod Biol Endocrinol. 2012; 10: 92, doi: 10.1186/1477-7827-10-92, indexed in Pubmed: 23159014.

19. Hamada A, Esteves SC, Nizza M, et al. Unexplained male infertility: diagnosis and management. Int Braz J Urol. 2012; 38(5): 576-594, doi: 10.1590/s1677-55382012000500002, indexed in Pubmed: 23131516.

20. van de, Steures P, Eijkemans MJ, et al. Role of semen analysis in subfertile couples. Fertil Steril. 2011; 95: 1013-1019.

21. Ramasamy R, Scovell JM, Kovac JR, et al. Fluorescence in situ hybridization detects increased sperm aneuploidy in men with recurrent pregnancy loss. Fertil Steril. 2015; 103(4): 906-909.e1, doi: 10.1016/j. fertnstert.2015.01.029, indexed in Pubmed: 25707335.

22. Esteves SC, Zini A, Aziz N, et al. Critical appraisal of World Health Organization's new reference values for human semen characteristics and effect on diagnosis and treatment of subfertile men. Urology. 2012 79(1): 16-22, doi: 10.1016/j.urology.2011.08.003, indexed in Pubmed: 22070891.

23. Turner KA, Rambhatla A, Schon S, et al. Male Infertility is a Women's Health Issue-Research and Clinical Evaluation of Male Infertility Is Needed. Cells. 2020; 9(4), doi: 10.3390/cells9040990, indexed in Pubmed: 32316195.

24. Chiu YH, Edifor R, Rosner BA, et al. EARTH Study Team. What Does a Single Semen Sample Tell You? Implications for Male Factor Infertility Research. Am J Epidemiol. 2017; 186(8): 918-926, doi: 10.1093/aje/kwx169, indexed in Pubmed: 28541378.

25. Rylander L, Wetterstrand B, Haugen TB, et al. Single semen analysis as a predictor of semen quality: clinical and epidemiological implications. Asian J Androl. 2009; 11(6): 723-730, doi: 10.1038/aja.2009.64, indexed in Pubmed: 19823177.

26. Barratt CLR, Björndahl L, De Jonge $C J$, et al. The diagnosis of male infertility: an analysis of the evidence to support the development of global WHO guidance-challenges and future research opportunities. Hum Reprod Update. 2017; 23(6): 660-680, doi: 10.1093/humupd/dm×021, indexed in Pubmed: 28981651.

27. Shiraishi K, Matsuyama H. Effects of medical comorbidity on male infertility and comorbidity treatment on spermatogenesis. Fertil Steril. 2018; 110(6): 1006-1011.e2, doi: 10.1016/j.fertnstert.2018.07.002, indexed in Pubmed: 30396536.

28. Efrat $M$, Stein $A$, Pinkas $H$, et al. Dietary patterns are positively associated with semen quality. Fertil Steril. 2018; 109(5): 809-816, doi: 10.1016/j. fertnstert.2018.01.010, indexed in Pubmed: 29778381.

29. Palermo $G$, Joris $H$, Devroey $P$, et al. Pregnancies after intracytoplasmic injection of single spermatozoon into an oocyte. Lancet. 1992; 340(8810): 17-18, doi: 10.1016/0140-6736(92)92425-f, indexed in Pubmed: 1351601. 